\title{
Endogenous Credit and Investment Cycles with Asset Price Volatility
}

\author{
Francesco Carli ${ }^{1} \quad$ Leonor Modesto ${ }^{2}$ \\ ${ }^{1}$ Católica Lisbon School of Business and Economics \\ ${ }^{2}$ Católica Lisbon School of Business and Economics \& IZA
}

Second International Conference of the Society for Economic Measurement

July 22, 2015 


\section{Question}

- Can credit market frictions be a source of aggregate fluctuations?

- Financial sector perturbations vs. amplifications

- We study the influence of limited commitment on the emergence of indeterminacy and sunspots.

- With limited commitment asset prices can jump to accommodate for changes in expectations.

- Fluctuations in macroeconomic outcomes and asset prices are tied to aggregate shifts in market expectations. 


\section{The Environment}

- $t=1,2, \ldots$

- Two goods: capital good, consumption good.

- Each period :

- Perfectly Competitive sector $Y_{t}=F\left(K_{t}, L_{t}\right)$, where $\mathrm{F}$ linearly homogeneous.

- Capital used in production fully depreciates.

- New capital is produced,

- Consumption is non storable 


\section{Agents and endowments}

- 2 types of agents: $\begin{cases}\alpha & \text { workers } \\ 1-\alpha & \text { entrepreneurs }\end{cases}$

- Workers

- 1 unit of time in day and work for the representative firm receiving a wage $w_{t}$.

- Entrepreneurs

- No time (Don't work)

- Capital producing technology

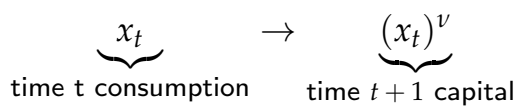

- Assume $1>v>0$.

- Workers can not operate this technology but buy claims on next period capital. 


\section{Credit markets}

Every period, a competitive credit market opens.

- Entrepreneurs and workers can trade claims (bonds) on future capital

- $q_{t}$ price of each bond: consumption goods needed at time $t$ to purchase a claim on 1 unit of capital at time $t+1$

- $k_{t+1}^{W}$ and $k_{t+1}^{E}$ denote workers and entrepreneurs net demand for bonds

- Limited commitment: entrepreneurs can repudiate their debt and divert resources from their investment technology. 


\section{Workers problem}

- Recursive formulation of worker's problem:

$$
\begin{aligned}
U_{t}\left(k_{t}^{W}\right)=\max _{\left(c_{t}^{W}, k_{t+1}^{W}\right)} & \log \left(c_{t}^{W}\right)+\beta E_{t}\left[U_{t+1}\left(k_{t+1}^{W}\right)\right] \\
\text { s.t. } & c_{t}^{W}+q_{t} k_{t+1}^{W}=w_{t}+r_{t} k_{t}^{W}
\end{aligned}
$$




\section{Entrepreneur's limited commitment}

- Entrepreneurs can divert resources and consume after credit market closes

- Hidden consumption yields $(1-\theta)$ utility for each unit of consumption

- Upon default, assume perpetual exclusion from credit markets.

- Entrepreneurs deviation payoff:

$$
\widetilde{V}_{t}\left(S_{t}^{E}, k_{t+1}^{E}\right)
$$




\section{Entrepreneur's problem}

- Recursive formulation of entrepreneur's problem:

$$
\begin{aligned}
V_{t}\left(k_{t}^{E}, x_{t-1}\right)=\max _{\left(c_{t}^{E}, x_{t}, k_{t+1}^{E}\right) \in \Re_{+}^{2} \times \Re} & c_{t}^{E}+\gamma E_{t}\left[V_{t+1}\left(k_{t+1}^{E}, x_{t}\right)\right] \\
\text { s.t. } & c_{t}^{E}+q_{t} k_{t+1}^{E}+x_{t}=r_{t}\left[x_{t-1}^{v}+k_{t}^{E}\right] \\
& q_{t} k_{t+1}^{E}+x_{t} \geq 0 \\
& \gamma E_{t}\left[V_{t+1}\left(k_{t+1}^{E}, x_{t}\right)\right] \geq \widetilde{V}_{t}\left(S_{t}^{E}, k_{t+1}^{E}\right)
\end{aligned}
$$




\section{Equilibrium}

\section{Definition}

An equilibrium with limited commitment consists in sequences $\left(c_{t}^{W}, k_{t+1}^{W}\right)_{t=0}^{\infty},\left(c_{t}^{E}, k_{t+1}^{E}, x_{t}\right)_{t=0}^{\infty},\left(q_{t}, r_{t}, w_{t}\right)_{t=0}^{\infty}$ such that

- $\left(c_{t}^{W}, k_{t+1}^{W}\right)_{t=0}^{\infty}$ and $\left(c_{t}^{E}, k_{t+1}^{E}, x_{t}\right)_{t=0}^{\infty}$ solve workers and entrepreneurs problem respectively;

- Capital and labor earn their marginal product;

- Credit market clears

$$
\alpha k_{t+1}^{W}+(1-\alpha) k_{t+1}^{E}=0
$$

- Capital evolves according with

$$
K_{t+1}=(1-\alpha) x_{t}^{v}
$$




\section{Stationary Equilibria}

- Workers and entrepreneurs trade bonds

- No default constraint is slack, and $S^{E}=0$.

- No default constraint binds, and $S^{E}=0$.

- No default constraint binds, and $S^{E}>0$.

- Workers and entrepreneurs do not trade bonds, and $S_{t}^{E}>0$. 


\section{Stationary equilibria}

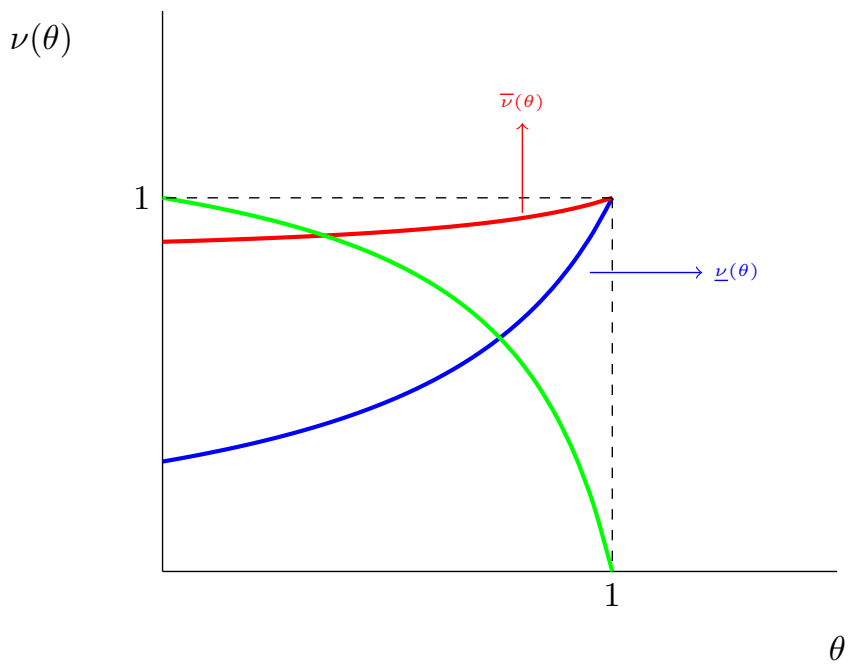




\section{First Best Local Dynamics}

- The price of new capital is a function of $x_{t}$ :

$$
q_{t} \equiv q\left[x_{t}\right]=\frac{1}{v x_{t}^{v-1}}
$$

- In the end, the dynamics of the system in the first best are:

$$
\begin{aligned}
\frac{E_{t}\left(c_{t+1}^{W}\right)}{c_{t}^{W}}=\frac{\beta f^{\prime}\left(z\left[x_{t}\right]\right)}{\left.q\left[x_{t}\right]\right)} & \\
c_{t}^{W}+q\left[x_{t}\right] k_{W}\left[x_{t}\right]= & f\left(z\left[x_{t-1}\right]\right)-z\left[x_{t-1}\right] f^{\prime}\left(z\left[x_{t-1}\right]\right) \\
& +f^{\prime}\left(z\left[x_{t-1}\right]\right) k_{W}\left[x_{t-1}\right]
\end{aligned}
$$

- Investment is a predetermined variable, consumption is a non-predetermined variable.

- Only if the steady state is a sink, we will have indeterminacy. 


\section{First Best System Local Dynamics}

\section{Proposition}

If the no default constraint is slack, the stationary equilibrium with bonds is a saddle.

\section{Corollary}

There is a unique convergent path to the steady state. The dynamic model is locally determinate, so that endogenous fluctuations do not emerge. 


\section{Local dynamics with a binding no-default constraint, bonds, and $S^{E}=0$}

- Investment is now pinned down by a forward looking no-default constraint:

$$
(1-\theta) x_{t}=E_{t}\left\{\gamma c_{t+1}^{E}+\gamma(1-\theta) x_{t+1}\right\}
$$

and the price is no-longer linked to fundamentals

$$
q_{t}=q_{t}\left(c_{t+1}^{W}, x_{t}, x_{t+1}\right)
$$




\section{Dynamical System}

- We finally obtain

$$
\begin{gathered}
(1-\theta) x_{t}=E_{t}\left\{\gamma r\left(x_{t}\right)\left[x_{t}^{v}-\frac{\alpha}{1-\alpha} \frac{c_{t+1}^{W}+\frac{1-\alpha}{\alpha} x_{t+1}-w\left(x_{t}\right)}{r\left(x_{t}\right)}\right]\right. \\
\left.+\gamma(1-\theta) x_{t+1}\right\} \\
E_{t}\left\{\frac{c_{t+1}^{W}}{c_{t}^{W}}-\frac{\beta \alpha\left[c_{t+1}^{W}+\frac{1-\alpha}{\alpha} x_{t+1}-w_{t+1}\left[x_{t}\right]\right]}{(1-\alpha) x_{t}}\right\}=0
\end{gathered}
$$

- Both consumption and investment are non-predetermined variables. 


\section{Local dynamics with a binding no-default constraint, bonds, and $S^{E}=0$}

Proposition

Assume that $\gamma \geq \min \{s,(1-\theta) \beta\}$. Then the limited

commitment steady state with bonds and no collateral is a saddle.

Corollary

The limited commitment steady state with bonds and no collateral is always locally indeterminate. 
Idea

- There are an infinite number of combinations of initial values for both state variables such that

- The system is on the stable arm,

- The system will always converge to the steady state.

- Given an initial value $x_{0}$, investment converges to a unique steady state $x_{B N C}$ and consumption to $c_{B N C}^{W}$.

- However sunspots matter 


\section{Sunspot equilibria}

- Starting from the steady state, a forecasting error hits the economy.

- $x$ and $c$ are tied by so that the economy comes back to the stable arm, guaranteeing convergence to the steady state.

- Stochastic bounded equilibrium trajectories driven by expectations shocks are possible when the steady state is a saddle. 


\section{Sunspot equilibria}

- Add forecasting errors $e_{t+1}=\widetilde{x}_{t+1}-E_{t}\left(\widetilde{x}_{t+1}\right)$, with $E_{t}\left(e_{t+1}\right)=0$

- Local sunspot equilibria can be obtained by considering that $e_{t+1}$ follows an i.i.d. stochastic process of bounded support with small variance 


\section{Simulation Exercise}

\begin{tabular}{lc} 
Parameter & Value \\
\hline \hline$\beta$ & 0.99 \\
$\gamma$ & 0.92 \\
$\sigma$ & 2.5 \\
$s$ & 0.33 \\
$\theta$ & 0.60 \\
$\nu$ & 0.98 \\
$\sigma_{e}$ & 0.0185
\end{tabular}

- Sunspot shocks $\mathcal{N}\left(0, \sigma_{e}\right)$ i.i.d.

- $\sigma_{e}$ chosen to match variance in consumption growth 


\section{Findings}

- 500 draws of $\sigma_{e}^{t}$, compute average standard deviation of series.

- $\sigma_{x}>\sigma_{c^{\mathrm{W}}}$ : Investment more volatile than consumption

- $\sigma_{x}>3.1 \cdot \sigma_{y}$ : Investment more volatile than output

- Changes in marginal productivity make $r$ countercyclical, $w$ pro cyclical.

- $\sigma_{k^{\mathrm{W}}}=2.65 \cdot \sigma_{x}$ 


\section{Simulated Series}
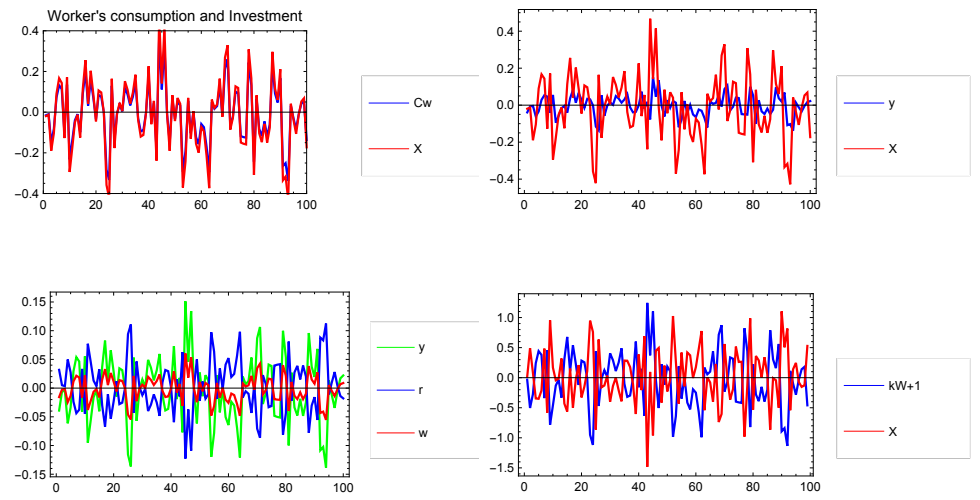


\section{Volatility of $q_{t}$}

$\sigma_{q}=8.05 \cdot \sigma_{y}$

- Because $v \approx 1$, without limited commitment

$$
q_{t}^{F B}=\frac{1}{v x^{v-1}} \approx 1
$$

- All the variability comes from the binding no-default constraint.

- Moody's BAA Corporate Bond Yield index: $\sigma_{q}=5.37 \cdot \sigma_{y}$ 


\section{Simulated Series}
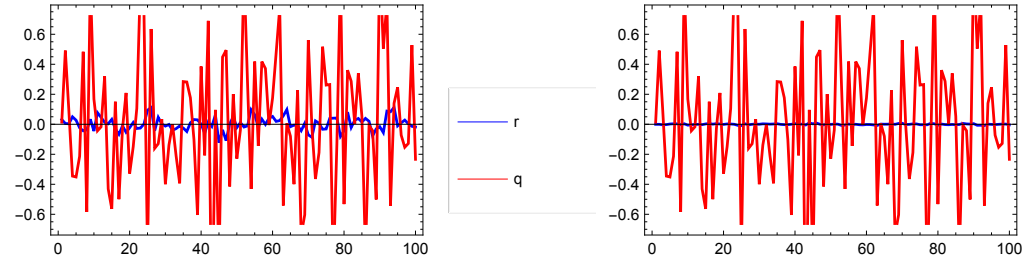


\section{Conclusions}

- Developed a framework to study dynamics in lending, production, and investment, with capital and limited commitment.

- With perfect credit markets, prices are pinned down by technology.

- With limited commitment

- Prices no longer pinned down by technology, but depend on expectations of future market conditions. 


\section{Conclusions}

Limited commitment introduces the possibility of

- Indeterminacy

- Endogenous fluctuations in credit, investment etc, driven by self fulfilling prophecies.

- Bond price volatility, consistent with data, in response to shifts in expectations. 


\section{Conclusions}

Policy recommendations?

- Changes in $v$ and $\theta$ can move the economy away from the indeterminacy region.

- What policy parameters can influence $v$ and $\theta$ ? 